and 1 had methylmalonic aciduria). Average duration of neutropenia was 6,43 months while average age at diagnosis was 19,6 months. During this study 227 (78,82\%) examinees were cured, $34(11,81 \%)$ were still being followed up and for 27 $(9,38 \%)$ of them we didn't know outcome. 39,24\% neutropenias were acute and $56,25 \%$ were chronic. According to the severity of neutropenia the distribution was $60,42 \%-26,39 \%$ - $12,85 \%$ (severe, moderate, mild). Average duration of neutropenia in cases of severe neutropenia (ANC $<0,5 \times 10^{9} / 1$ ) was 9,14 months, in moderate neutropenia (ANC $=0,5-1,0 \mathrm{x}$ $10^{9} / 1$ ) 4,09 months and in mild neutropenia (ANC > 1,0 $\mathrm{x}$ $\left.10^{9} / 1\right) 1,64$ months. We recorded infection during neutropenia in $232(80,56 \%)$ examinees while 88 (30,56\%) had noted infections before the onset of neutropenia.

Conclusion This study showed that $97,57 \%$ children had benign neutropenia and $78,82 \%$ were spontaneously cured during the research which are encouraging results. We noted that children with mild neutropenias and those who had no recorded infections during neutropenia had shorter average duration of neutropenia. In conclusion, most neutropenias of the early childhood are benign and have favorable outcome.

\section{APLASTIC CRISIS INDUCED BY HUMAN PARVOVIRUS B19 AS AN INITIAL PRESENTATION OF HEREDITARY SPHEROCYTOSIS IN A CHILD - A CASE REPORT}

Petra Ivančić* ${ }^{*}$ Maja Vrdoljak. Medicinski fakultet Sveučilišta u Zagrebu

\subsection{6/archdischild-2021-europaediatrics.325}

Background A transient, self-limiting aplastic crisis is a rare manifestation of parvovirus (PV) B19 infection, usually seen in patients with underlying haemolytic anaemias. The virus has a predilection for infecting the erythroid progenitor cells of the bone marrow resulting in their lysis and red cell aplasia, although white cell and platelet counts may also decline.

We herein report aplastic crisis induced by PV B19 infection unmasking hereditary spherocytosis in a boy.

Case Presentation A 11-year-old boy presented with high-grade fever, headache, drowsiness, sore throat, and a rash.

On admission he was conscious, but sleepy, drooling, with pale skin and conjunctivae. Physical examination revealed macular, somewhere petechial rash involving the neck and extremities, tachycardia, systolic murmur and hepatosplenomegaly.

Complete blood count revealed RBC of 2.34 x10e12/L, with haemoglobin concentration of $64 \mathrm{~g} / \mathrm{L}$ and reticulocytopenia, WBC $1.3 \times 10 \mathrm{e} 9 / \mathrm{L}$, and platelet count $75 \times 10 \mathrm{e} 9 / \mathrm{L}$. Spherocytosis was present on the peripheral blood smear.

Bone marrow aspirate showed suppressed erythropoiesis. The PV B19 infection was diagnosed by polymerase chain reaction (292 $000000 \mathrm{DNA}$ copies/ml of blood) and positive serology for specific anti-PV B19 IgM.

Osmotic fragility testing showed increased fragility of erythrocytes, which was consistent with the diagnosis of hereditary spherocytosis.

The boy was treated by blood and platelet transfusions and supportive care, and was discharged after 9 days of hospital care with improved blood count.

Conclusions PV B19 induced aplastic crisis can be the first manifestation of hereditary spherocytosis. PV B19 infection must be considered in the differential diagnosis in patients with acquired aplastic anaemia.

\section{AUTOSPLENECTOMY - CASE REPORT}

Dora Šercar*, Izabela Kranjěec, Nuša Matijašić. Department of Oncology and Hematology, Children's Hospital Zagreb, Zagreb, Croatia

\subsection{6/archdischild-2021-europaediatrics.326}

Introduction Autosplenectomy defines spontaneous splenic infarction leading to hyposplenism. It occurs mainly as a complication of sickle cell anemia, pneumococcal sepsis or systemic lupus erythematosus, but may also be associated with various other conditions. An anatomical variation of the spleen's position, the wandering spleen, has been reported as an underlying cause in less than $0.5 \%$ of autosplenectomy cases.

Case Report A 9.5-month-old female was admitted to the Department of Oncology and Hematology of the Children's Hospital Zagreb due to a prolonged fever of an unknown origin and splenomegaly. Laboratory findings detected profound normocytic anaemia, attributed to splenic sequestration. Abdominal ultrasound detected multiple hypoechoic areas in the spleen, indicating splenic infarction, confirmed by MR angiography. An extensive work-up excluded sickle cell anemia, thalassemia, hematological malignancies, myeloproliferative disorders, thrombophilia, autoimmune vasculitis, Kawasaki disease and infection as a cause of the condition. However, repeated ultrasound examination revealed an aberrant, ventrally positioned spleen, which most likely led to an inadequate blood supply and consequently splenic infarction. Antiplatelet therapy and antibiotic prophylaxis were initiated, along with pneumococcal and meningococcal vaccines. The patient is still monitored regularly, currently with normal hematological laboratory findings and none of the complications possibly attributed to hyposplenism.

Conclusion Autosplenectomy in children, although rarely, may result from an aberrant spleen's position. Congenital weakness of the splenic ligaments, allowing its mobility, causes torsion of the splenic artery, leading to blood supply failure and tissue damage. Given the wide differential diagnosis of splenic infarction, it is necessary to exclude numerous underlying medical conditions, primarily sickle cell anemia. A conservative approach is currently the treatment of choice. Hyposplenism, leading to susceptibility to sepsis caused by encapsulated bacteria, requires appropriate antibiotic prophylaxis and vaccination of such patients.

\section{Paediatric Intensive and Emergency Medicine}

\section{DIFFICULTIES EMERGING FROM THE END-OF-LIFE CARE IN THE PEDIATRIC INTENSIVE CARE UNITS}

Filip Rubic*, M Curkovic, S Jankovic, L Brajkovic, A Jozepovic, M Novak, B Filipovic-Grcic, A Borovecki. University Hospital Zagreb

10.1136/archdischild-2021-europaediatrics.327

Working in ICUs that involves care for critically ill children is inherently demanding. The intricacy of end-of-life issues in this setting adds additional layer of high demands that health care professionals are inadequately prepared for An interpretative, qualitative inquiry based on thematic data analysis using focus groups as data collection method was used in order to 
get insight into front line, health care staff experiences with end-of-life issues. The study was undertaken in three distinct research sites in the Republic of Croatia and involved health care staff participants (physicians and nurses) from six health care institutions (six NICUs and six PICUs).

A total of 21 physicians and 25 nurses participated in eight focus groups.

Analysis revealed two main themes, that were equal among professional groups as well as NICU and PICU units. Theme critically ill child consisted of child, family, myself, and other professionals subthemes. Theme end-of-life procedures consisted of subthemes: breaking point, decision-making, end-oflife procedures, 'spill-over' and the four walls of the ICU.

Perceptions and experiences of end-of-life issues by nurses and physicians working in NICU and PICU share multiple common characteristics.

Interrelatedness of high emotional and cognitive demands and burden associated with end-of-life issues in this setting seems to have a significant influence on personal and professional lives of professionals.

Additionally, high variability of end-of-life applied procedures, and various difficulties experienced during shared decision-making process, stresses the need for developing guidelines that will inform such a practice, while considering specific perspectives of everyone involved.

\section{A REVIEW OF EXPERT RECOMMENDATIONS ON END- OF-LIFE ISSUES IN PEDIATRIC INTENSIVE CARE SETTING}

Sunčana Janković*, Marko Curković, Dina Vrkić, Ana Jozepović, Bojana Nevajdić, Milivoj Novak, Štefan Grosek, Ana Borovečki. UHC Zagreb

\subsection{6/archdischild-2021-europaediatrics.328}

One of the most ethically challenging issues in modern medicine are the ones related to end-of-life care. This is especially evident in intensive care setting where healthcare professionals are often involved in decisions about withholding or withdrawing potentially life-prolonging treatment and/or decisions on alleviation of suffering with a possible life-shortening effects. In pediatric intensive care setting, including both neonatal and pediatric intensive care units, there are additional layers of complexity added to end-of-life issues, as patients and their close ones are especially vulnerable and issues around usability, reliability and validity of surrogate decision makers are widespread. These complexities create many tensions that results with high variability on how end-of-life issues are approached in theoretical discussions, handled in practice. Not only that there is a high variability in that sense on global scale, but there is high variability within similar cultural, social, legal and health care contexts, as well as even between different institutions, units, and health care professionals in the single context. This creates a growing need for standardized, clinical and professional guidelines, ones that will be informed by all stakeholders that are included in this process.

There are many recommendations and guidelines regarding treatment end-of-life care crated by national and transnational institutions, while only few of them considering pediatric intensive care setting. In order to systematically identify them a systematic literature search in bibliographic databases and grey literature sources was conducted. The constant comparative qualitative analysis was used in order to identify and extricate their ethical content including ethical positions, ethical arguments and corresponding ethical principles. The aim was to extricate main ethical challenges, to explore how they are dealt with (on a theoretical and practical level), and to extricate main arguments and justifications on which their recommendations are based. The emphasis was placed on how those guidelines are handling specific end-of-life care issues regarding palliative care and/or palliative/terminal sedation; withholding and withdrawing of treatment interventions; and, where applicable, intentional terminating of life. Finally, similarities and disparities between these guidelines are presented and discussed, while also considering their (dis)similarities with guidelines dealing with end-of-life issues in adult intensive care settings.

*This article is part of the research 'Values and Decisions at the End of Life', funded by Croatian Science Foundation.

\section{DRUG INDUCED CARDIAC ARREST IN AN ADOLESCENT WITH HYPERTROPHIC CARDIOMYOPATHY?}

Toni Matić*, Ivan Bambir, Dalibor Šarić, Sanja Dorner, Miran Cvitković, Slobodan Galić, Filip Rubić, Sandro Dessardo, Milivoj Novak. Department of Paediatrics, University Hospital Centre Zagreb

10.1136/archdischild-2021-europaediatrics.329

We present an adolescent with newly diagnosed hypertrophic cardiomyopathy who suffered cardiac arrest with ventricular fibrillation.

We assume these conditions could have been caused by substances commonly abused by adolescents: anabolic steroids and synthetic cannabinoids Previously healthy, muscular, seventeen-year-old adolescent was examined by a paediatric cardiologist because of chest pain. Asymmetric hypertrophic cardiomyopathy without outflow tract obstruction was diagnosed, with sinus rhythm in 24 hour holter electrocardiogram. Avoidance of sport activities and bisoprolol therapy was suggested, which the patient did not comply to.

There were no heart diseases in the family history.

Four months after, the patient suddenly collapsed while sitting.

Resuscitation was started immediately and defibrillation was used because of ventricular fibrillation. Patient was transferred to the hospital. After additional 80 minutes of resuscitation with recurring ventricular fibrillation, a stable pulse was regained. Since the hemodynamic stability was not achieved with high catecholamine doses, venoarterial extracorporeal membrane oxygenation (ECMO) was administered, which stabilized the hemodynamic status. Day after, the ultrasound showed left ventricle ejection fraction of $45-50 \%$, and a thickened 26-milimeter septum with hyperechogenic and hypokinetic middle part, possibly attributed to ischemic necrosis. Four days later ECMO was discontinued. On day 32, the patient was discharged from the hospital in a good condition with a normal neurological status, and with implanted automatic cardioverter defibrillator.

Three months after the discharge, ultrasound showed a 15 milimeter septal thickness and left ventricle ejection fraction of $62 \%$. Cardioverter defibrillator was not activated after implantation. The patient's appearance was less muscular than at the time of incident.

Although we were not able to prove the presence of anabolic steroids, patient's muscular appearance and a newly 